\section{CROONIAN LECTURES}

\author{
ON
}

\section{MIND, BRAIN, AND SPINAL CORD, \\ IN CERTAIN MORBID CONDITIONS.}

Delivered at the Royal College of Physicians, March 1873.

By C. B. RADCLIFFE, M.D., F.R.C.P.,

Physician to the Westminster Hospital, and to the National Hospital for the Paralysed and Epileptic : etc.

LECTURE III.

THE subjects to which I would wish to direct attention in the present lecture are two in number. The first is a disorder which often occurs in practice, but which as yet, so far as I know, has escaped distinct recognition-a disorder which I would venture to call cerebral exhaustion. The second is a disorder closely akin to this, for which spinal exhaustion would seem to be a fitting name-a disorder often disguised under the mask of hysteria so called. In what I have to say there will be little about spinal exhaustion, for the hour allotted to me will be very nearly gone when I have said what I want to say upon the subject with which I choose to begin-namely, cerebral exhaustion; but this matters little in reality, for much of what is left unsaid would be little more than a repetition of what will be said.

\section{CONCERNING CEREBRAL EXHAUSTION.}

The symptoms of cerebral exhaustion are numerous and various; but, as I hope to show before I have done, neither vague nor inconstant. In considering them it matters little what plan is pursued, provided they are all included in it. It is, indeed, enough to take them seriatim, with little or no regard to any method of classification and this is really what I propose to do. Or, if I do any more than this, it is merely to put them in certain groups, four in number, in which, without any sufficient reason, perhaps, they have come to arrange themselves practically in my mind.

Failure of memory, and of mental energy generally-sleepiness or the reverse-depression of spirits-and unusual irritability of the temper -are the symptoms, in all probability, which first arrest the attention and which I would venture to place in the first of the four groups I have mentioned.

The symptom first named-failure of mental energy, of memory most particularly - must be looked upon as the symptom of symptoms. Where the patient has no occasion to exercise his mind, this symptom may not force itself upon the attention ; but not so in the contrary case. Here, without any questioning on the subject, the complaint made is almost sure to be that the "headwork", which was once easy, has become all but impossible, and that the little work done is not well done. It is no longer possible to fix the thoughts to the task in hand; the thoughts themselves have lost all vividness, and working in a hurry, working against time, has become a thing scarcely to be thought of, any pressure in this direction producing a state of helpless distress analogous to nightmare, instead of being, as it ought to be, and as it once was, a stimulus to exertion. The feeling is, that rest must be had at any price. Or the mental inactivity may show itself in other ways-in loss of memory, most particularly and most commonly. But it is not necessary to multiply illustrations of the way in which this inactivity may declare itself In one way or another, more or less obvious and unmistakable, it does show itself in all cases of cerebral exhaustion : the fact is not to be questioned, and it is only with the broad fact that I have to do at the present moment.

Cerebral exhaustion, again, is very likely to show itself in increased sleepiness or the reverse. Usually, the brain wants more sleep to enable it to do its work. It is very easy, however, to make a mistake upon this point. Nothing can be more certain than that sleep at all in excess, instead of refreshing, only stultifies; and what at first appears to be cerebral exhaustion may now and then turn out to be in reality no more than this stultification, the natural result of yielding to a lazy disposition to sleep. Still, sleepiness may be, and often is, a marked symptom in cerebral exhaustion, especially where the patient previously was anything but sleepy, and where he now frets at finding that he cannot keep awake as he once did. Or the cerebral exhaustion may show itself in wakefulness rather than in sleepiness-in wakefulness, which often, before advice is sought after, has led to a habit of drugging or drinking at bedtime. And herein arises very frequently a grave complication, for after a time it is not a little difficult to decide whether the symptoms have to do with cerebral exhaustion or with this habitwhether the cerebral exhaustion is a primary disorder which has led to this habit, or merely or mainly a secondary effect of the habit. That cerebral exhaustion is infinitely aggravated by such a habit, there can be no doubt; indeed, the longer I live the more I am convinced that there is scarcely any practice more mischievous than that of having recourse, under the least sleeplessness, to the medicine-chest or the cellaret, and that cerebral exhaustion is only one of the many ways in which in the end the system is likely to be compromised by yielding to it.

Depression of spirits is another symptom very commonly met with in cases of cerebral exhaustion-one of the earliest in making its appearance, in all probability. As in insanity, so in cerebral exhaustion, melancholy, more or less marked in degree, is by far the most prominent mental mood. The patient is "out of heart", to say the least, and very much disposed to give up in the struggle, whatever that may be, in which he is engaged.

Along with depression of spirits there is also very often unusual irritability of temper. There is a marked change in this respect-a person previously placid and good-tempered becoming irritable and easily provoked to anger, or an irritable person more irritable. The irritability is unusual-that is to say, it is either an altogether new mood of mind, or else an old mood greatly magnified.

After these symptoms, and forming another equally arbitrary group, those which next claim attention are-a continued craving for food and stimulating drinks, for the latter especially; lessened locomotive power; lessened control over the bladder; lessened sexual activity; inequalities of circulation; and perhaps an aged appearance.

A common symptom in many cases of cerebral exhaustion is, without question, a continual craving for food and for stimulating drinks, for the latter more especially. The patient will have it that he must sink unless he be constantly taking food; and often he will go on eating whenever he can, until his stomach resents, in some unmistakable way, this disorderly mode of procedure. Or the craving is, not for food, but for stimulating drinks. And no wonder that it should be so ; for the feeling of sinking which leads to it is met by stimulants in a way in which it is not met by food and rest merely, especially in the case where the stomach has been first tired out by the yielding to the craving for food. In many cases, no doubt, there is no such craving as this, and no yielding to it if it exist; and yet, even in these cases, a suspicion of its latency is often suggested by the eagerness of the patient to know, not so much what he may eat, and how much, but what he may drink, and how much. In too many cases, also, there is evident dissatisfaction at being restricted within moderate bounds in this matter. Where these moderate bounds may be is, of course, not always easy to say. Of this, however, I am sure, that they are often overstepped, and that this overstepping has very frequently not a little to do with bringing about cerebral exhaustion and many other grave derangements of the health. As it seems to me indeed, it is impossible to exaggerate the evils arising from the habit of a little exceeding the bounds of moderation in the use of alcoholic drinks, especially when it shows itself in the taking of "pick-me-ups" of various sorts between meals. The case is like spurring a horse needlessly. For a time, perhaps for a long time, all goes on well, and then comes a breakdown in which the spur fails to tella breakdown, it may be, in which it may be impossible ever to get up again under any amount of spurring. Altogether, indeed, I am very much disposed to think that occasional downright intoxication is a less grave evil than habitual transgression a little beyond the bounds of moderation in the use of alcoholic drinks. At all events, the fact remains, that a continual craving for food and for stimulating drinks, for the latter especially, is a common symptom in many cases of cerebral exhaustion, and that very often the difficulties of diagnosis and treatment are not a little complicated on this account.

As in neuriasis, so in cerebral exhaustion, a very early and prominent symptom is lessened control over the bladder. The patient cannot hold his urine as long or as well as he did formerly; his sleep may be much disturbed and broken for this reason; or he may have to wait a considerable time before the bladder will act. Often, too, the urine is neutral and over-abundant. Much distress may be caused by this state of things, and not unfrequently there may be a suspicion in the mind of the patient that he is suffering from disease of the kidney or bladder, when, as the sequel shows, he is really suffering from cerebral exhaustion. As the sequel shows, I say-for, as this state of exhaustion passes off, the vesical disorder passes off likewise.

Lessened control over the bladder is almost always associated with lessened locomotive power. Now and then, however, either of these infirmities may exist without the other, and that, too, in no trifling degree of development. Usually there is no difficulty in detecting the 
failure in locomotive power. There is, if no more, the loss of a certain springiness in the gait ; there may be as much as an actual copying of the heavy shuffling manner of using the feet which belongs to advanced age. Walking exercise, no longer a pleasure, has become a thing to be dreaded, the mere thought of having to walk often making the legs aching and heavy, and not the legs only, but the head and the whole body also. A stick is felt to be almost a necessary help in getting along. As regards locomotion, indeed, the state of things in cerebral exhaustion is that which suggests, more or less painfully, the idea of old age. Nor is this regarded as a matter of secondary importance by the patient. On the contrary, it is the particular failure to which he is likely to call attention at the very beginning of his story, if he be allowed to tell this in his own way.

In many cases of cerebral exhaustion, also, there is marked inactivity in the sexual function. Often, indeed, this function for the time is in total abeyance. The patient is very likely to say that he does not know what has come to him in this respect, even before he says anything about the two symptoms which have been last mentioned - the lessened power over the bladder, and the lessened locomotive power. I remember, indeed, no single case to which I would give the name of cerebral exhaustion, in which marked inactivity of the sexual function was not an early and very prominent symptom.

Incqualities of circulation, as shown in cold hands and feet, in local congestions of this organ or that, and in various other ways, may also be mentioned as deserving a place among the symptoms of cerebral exhaustion. Artificial warmth is felt to be more necessary than formerly, or at least better protection from cold ; cold is more apt to be followed by local congestive reactions, in the head, it may be, or anywhere. The vaso-motor system of nerves does its work less perfectly, and a state of undue contraction or undue relaxation of the vessels is the result, the latter state easily following upon the former; slight exhaustion, however brought about, being a sufficient cause for the change in either case, whenever there is a state of things which may be spoken of as cerebral congestion.

An aged appearance is another point which is likely to be observable in persons suffering from cerebral exhaustion. These persons are usually almost always advanced or advancing in years-years which will have their varied and well known marks ; but, whatever the age of the patient, whether this be actually advanced or not, what is noticed is that these marks are exaggerated, and, for the particular age, premature also. In cases of cerebral exhaustion, indeed, it is no uncommon thing to find that the patient is several years younger than he appears to be.

As entering into another group, and as marking a somewhat more advanced stage of the disorder, the symptoms which next demand attention are-malaise at the back of the head and neck, vertigo, disposition to tears, immoderate yawning, and bouts of breathlessness and faintness.

A very frequent symptom in cases of cerebral exhaustion is a feeling of malaise at the back of the head and neck. This feeling may amount to actual pain ; more generally it takes the shape of weight. Often it is a very distressing symptom, which cannot be forgotten during the day, and which even gives a nightmare-like complexion to the dreams during sleep. Often, too, it is distinctly connected with head-work, and only let this be suspended, and, if not absent altogether, it is all but forgotten.

In very many cases of cerebral exhaustion, also, a feeling of zertigo is of frequent occurrence. Any trifling disorder of the stomach is apt to show itself in this way, or any unusual bodily or mental effort or commotion. Very often it happens only or chiefly on getting up in the morning, when for the moment it may be supposed that the brain is re. ceiving a little less blood than it had received while in the recumbent position. Or it may happen in the act of stooping or straining, when the brain may be supposed to be somewhat congested. As a rule, however, it would seem to be necessary to associate vertigo with a bloodless, rather than a bloodshot, state of the brain, and to seek for a remedy in something which will rouse the circulation effectually. Nor is a different conclusion to be drawn from the history of the case in which there is more or less congestion along with this vertigo ; for this is sure to be venous rather than arterial-a consequence, in all probability, of simple want of power in the circulation.

Another symptom often present in the cases under consideration is andue disposition to tiars. The eyes fill and the lips quiver under the least provocation to such a display of feeling, or without it. In anyone who is naturally very emotional this symptom, of course, means very little, but not so in a person who exhibits other signs of cerebral exhaustion, and who previously had a reasonable amount of control over his feelings. In this case, as a rule, nothing can be more ominous. Imperfect control over the emotions, however, does not always have this serious significance, even in this case. I have known many patients with jaded brains in whom this symptom was present and prominent who recovered the full command over their feelings as the brain-power returned, and who have not relapsed as yet. Still, unfortunately, the rule would seem to be that cerebral exhaustion has already become a very unmanageable disorder, and that it is tending to pass into that still graver form of brain-disease of which general paralysis is the extreme manifestation, when undue disposition to tears stands out at all conspicuously among its symptoms.

As I am reminded by Dr. Farre, immoderate yawning may also deserve a passing notice as a symptom of cerebral exhaustion. Often, no doubt, yawning may be no more than a bad habit, and never, perhaps, is it of marked significance as a symptom. Still yawning may be more than a bad habit, and when it is so, especially if it be at the same time something new to the patient and sumething which cannot well escape notice, then it may point to a jaded brain-may deserve a place among the symptoms of cerebral exhaustion, that is to say.

In very many cases of cerebral exhaustion, in those perhaps more especially in which an attack of hemiplegia is imminent, there are often marked bouts of breathlessness and faintness. The patient while talking suddenly comes to a stop - to a standstill, also, if he happen to be walking at the same time. He feels as if for the life of him he could not say another word or take another step without giving himself time to recover breath. He may feel faint, but it is the want of breath of which he is most conscious, and most disposed to complain. His wind has gone, and any continued effort in talking, or walking, or stanaing-in standing, most of all, tries him in a way he cannot account for. Often he will not be convinced that his lungs or heart are not seriously wrong, and occasionally what is said of him by his medical advisers is calculated to confirm him in this conviction. He may even be sent to spend the winter in a warm climate for supposed lungweakness-I have known several such cases-when his disorder was nothing more than cerebral exhaustion about to issue in hemiplegia, and when all that was wanted was, not some sunny and genial spot far away where a good deal of exercise might be taken every day, but rest in an arm-chair at his own fireside. I have known several patients in such case who have derived no benefit from change of climate, so far as their bouts of breathlessness were concerned, but who at once became well in this respect when compelled to keep still by an attack of paralysis. And often and often have I seen the same thing happen - the bouts of breathlessness and all the other symptoms of apparent lung or heart weakness passing off-after an attack of hemiplegia. How this happens it is not easy to say. It may be that one great cause of the breath being affected in this manner is over-exertion from walking or standing, and that this is obviated by the paralysis. And certainly this is no irrational supposition, for the very occurrence of hemiplegia shows that the power of the brain was gravely compromised in the direction of walking and standing. Indeed, it may be supposed that the hemiplegia itself, as well as the bouts of breathlessness, might have been prevented if more care had been taken to economise the powers of a jaded brain in the matter of walking and standing. The latter trouble may certainly be in great measure prevented by doing this. At all events the fact remains, that marked bouts of breathlessness and faintness, independent as it would seem of any grave trouble in lungs or heart, must be included among the symptoms of the disorder of which I am endeavouring to sketch the outline, namely, cerebral exhaustion.

And, lastly, there is a group of symptoms of still graver importsymptoms belonging, as a rule, to a still more advanced stage of the disorder-namely, epileptiform attacks of one kind or another; transitory hemiplegia, transitory lightheadedness, transitory coma.

Epileptiform symptoms must certainly be included among the symptoms of cerebral exhaustion. Very often these may be overlooked for a short time, as when they happen under the guise of hidden seizures during sleep, or as transient flashes of petit mal-flashes often so transient as to be unnoticeable, unless a competent observer may happen to be looking in the patient's face at the moment. Very often all that is noticeable may be fits of unaccountable sleepiness, followed by forgetfulness, or lightheadedness, or weakness, with numbness or tingling, it may be of a hemiplegic character. Hidden seizures, in a word, would seem to be the rule rather than open seizures; still, not unfrequently the attacks are open enough, with all the most -marked characters of the fully developed epileptic or epileptiform paroxysm. As a rule, also, these attacks would seem to be connected with a bloodless rather than with a congested state of the brain. It is, I believe, a mistake ever to connect them with an over-active state of circulation in the brain. The immediate precursor of the perfect form of the paroxysm is a sign which is somewhat difficult to catch-corpse-like 
paleness of the countenance. Delasiauve was the first to notice this phenomenon. Trousseau insists upon it as a mark which distinguishes true epilepsy from feigned epilepsy. "Il est une signe," he says, "qui se produit au moment de la chute, qui n'est imitable pour personne; c'est la pâleur très prononcée cadavérique, qui couvre pour un instant la face épileptique. Nous ne la voyons pas, parceque nous arrivons toujours trop tard, alors que la face est déjà d'une rouge très prononcée." And I can fully corroborate the correctness of these statements. In fact, the general form of the epileptic or epileptiform paroxysm, the haut mal, begins in the same way as the partial form, the petit mal, for it is allowed by all that cadaverous pallor of the countenance is the initial symptom in cases of petit mal. Moreover, I can testify to the existence of a corresponding pallor at the same time deep down in the eye; for on several occasions, while happening to be examining the eye with the ophthalmoscope when an attack of petit mal has come on, I have seen the pupil dilate and the vascular blush in the fundus become quite pale. This I have seen again and again, for not unfrequently the ophthalmoscopic examination will of itself bring about an attack of petit mal where there is much predisposition to it. And, certainly, I know no evidence of a contrary character ; none to connect the epileptiform disorder, haut mal or petit mal, with a congestive state of the brain, either active or passive ; none, certainly, in the epileptiform disorder, which has to do with cerebral exhaustion. There may be more or less passive venous congestion; but this really means weakness of the circulation, and confirms rather than contradicts the inference already drawn, that the attack has its origin in failure of the circulation, not in active congestion of any kind anywhere. Indeed, it would appear that the cases of cerebral exhaustion in which there are congestive appearances in the head are, as a rule, not the cases in which this exhaustion declares itself in epileptiform trouble of any sort.

Not unfrequently, also, cerebral exhaustion makes itself known in a still more alarming way, even in transitory hemiplegia. It is no uncommon thing for a patient suffering from this disorder to have an attack in which, as in hemiplegia from apoplexy, he completely, or all but completely, loses power and feeling in the arm and leg of one side of the body, and in one side of the face, and in which his speech is lost and his tongue turned in the same way. Usually, however, the attack is not so complete as this, and often it shows itself only in a little numbness or tingling, with just a suspicion only of a loss of voluntary power, in the parts usually affected. In any case it may be difficult not to associate a first attack with apoplexy, or softening, or other grave organic mischief in the brain ; indeed, it is only after a certain time has elapsed, and the history of the patient supplies proof that the symptoms may again and again pass off speedily, and again and again return, that a certain diagnosis is possible. And even in this case it may happen that an attack which does not pass off may follow several apparently similar attacks which did pass off. I knew, for example, an old gentleman who had right hemiplegia with aphasia for six months before death, from - as it appeared on post mortem examination-extensive apoplectic effusion in the left hemisphere of the brain, and who, during the previous twenty years of his life, had no less than twelve distinct attacks of the same sort, only less complete in degree, each of which, after lasting from two to ten days, passed off completely. To some extent, perhaps, the diagnosis of hemiplegic symptoms from cerebral exhaustion may be facilitated by the presence of other symptoms belonging to this disorder, but not always to any great degree, for hemiplegia from apoplexy, or softening, or other grave organic lesion of brain, may also be ushered in by symptoms of cerebral exhaustion : indeed, for the most part, all that can be done is to give the patient the benefit of the doubt, and to wait in the hope that the attack may prove to be transitory; and, in short, all I can say in addition is this-that, in reality, these transitory attacks are much more frequent than is commonly supposed-that many of them come and go very much as epileptiform convulsions come and go, as it were paroxysmally - as if, indeed, there were, what there may well be, in fact, some common cause underlying the hemiplegic and the epileptiform condition.

Delirious ziandering is another symptom requiring more than a pass. ing notice. Sometimes-when the patient is old especially-this, in. deed, may be a very conspicuous symptom, the state then being not remotely akin to that which culminates in dotage. Usually, however, it is at once more transient and less conspicuous, in which case it may have to do with some epileptiform seizure, hidden or otherwise, or merely with a lessened tolerance for stimulants - a quantity before easily tolerated, if not actually taken with advantage, now giving rise to a state of intoxication. In this direction the head is not so "strong" as it used to be, and for this reason-wine more easily shows itself to be the mocker, which it is so frequently. In the majority of cases, however, there is reason to believe that this temporary aberration of mind of which I am speaking, especially when recurrent, points to the epileptiform basis of which I have spoken; and that in this respect the his. tory of mental aberration from cerebral exhaustion agrees substantially with that of mental aberration in other forms.

Another symptom of cerebral exhaustion, and the last to which I would wish to direct attention, may be transitory coma-a state often only distinguishable from that which attends upon apoplexy, or certain conditions allied to it, by the fact that it may presently pass off com. pletely, to return again and again, and again and again to pass off, as completely it may be. Here, as with the hemiplegia and the delirious wandering already mentioned, there is evidently an epileptiform basis. With the coma, however, more frequently than with the two other states which have been named, there may be a more frequent and obvious connexion with a state of cerebral congestion-a closer connexion with apoplexy-than in the other cases. Still, as Trousseau has pointed out, this congestive state is not always beyond question, and what is only certain is this - that often the coma is to be explained most easily in the way in which the coma of epilepsy has to be explained. But be this as it may, there is a coma connected with cerebral exhaustion which is not so serious in its consequences as the coma dependent upon apoplexy and certain degenerative changes in the brain, and for which the treatment is likely to be different in many respects from that which would be called for in coma associated with cerebral pressure-a state of coma which may pass off without leaving the patient much the worse for what had happened to him. While the coma continues it may be very difficult to pronounce positively as to its nature or cause. My own conviction is, that coma from simple cerebral exhaustion is a common form of the disorder, and that very many cases which end in apoplexy, or other structural changes in the brain, may begin in this way; and most certainly I should give the patient the benefit of the doubt, and deal with the case as if dependent simply upon cerebral exhaustion, as long as I could cling to this view. In a case where there was not very obvious paralysis of one side of the face-where the face, and the two eyes especially, were not drawn sideways; where there was not much stertor and congestion of the face and scalp; where the urine and fæces were retained for a reasonable time; where symptoms of sinking, or asphyxia were slow to declare themselves; where the attack did not happen, as is often the case with apoplexy, in the night-I should always be very much disposed to hope that the coma might prove to be dependent upon cerebral exhaustion simply, and that recovery might be expected, even complete recovery. As long as I could do so, indeed, I would give the patient the benefit of the doubt. What I contend for is, that this transitory coma from cerebral exhaustion is more common than it is generally supposed to be, and that it is of great importance that this fact should be more clearly recognised. Again and again have I seen cases of coma from supposed apoplexy, which had been virtually or actually abandoned as hopeless, which cases have done well in every way when the idea of cerebral exhaus. tion as a possible cause was realised and acted upon. Again and again I have seen a case of coma of this kind do well, when, in place of keeping the head high with ice applied to it, the head has been lowered, the ice removed, and coffee or tea-the most anti-comatose of all agents-given by injection, with or without a moderate allowance of alcohol, as the case might be. At all events, the fact remains that cases, often mistaken for the worst forms of coma, even for that dependent upon copious apoplectic effusion within the brain, may prove to be no more than a consequence of cerebral exhaustion, which may pass off completely and presently; and what I contend for is, that every case of coma should be read in this way until the contrary conclusion is forced upon the mind by the unsatisfactory progress of the disorder-that the patient should always have the benefit of the doubt, in fact-and that, especially, a long time should be spent in any case in coming to the conclusion that the coma is connected with cerebral pressure, which pressure is to be relieved by violent purging or violent depletory measures of any sort.

From this hasty survey, then, it may be gathered that the various symptoms of cerebral exhaustion may be; in the first group-failure of memory and of mental energy generally, sleepiness or the reverse, depression of spirits, unusual irritability of temper; in the second group -craving for frequent supplies of food and stimulating drinks-for the latter especially-lessened locomotive power, lessened control over the bladder, lessoned sexual activity, unequal distribution of blood, an aged appearance ; in the third group-malaise in the back of the head and neck, vertigo, undue disposition to tears, immoderate yawning, bouts of breathlessness and faintness; in the fourth group-epileptiform symptoms, transitory hemiplegia, transitory delirious wanderings, transitory coma. 
Of course all these symptoms are never present in the same case. Of course there is very great apparent dissimilarity in many cases, from the endless differences in the way in which particular symptoms are present or absent, and in which the symptoms actually present are associated. Still, for the most part, there can be no insuperable difficulty in the matter of diagnosis. There is, however, always the possibility that the symptoms may mean more than mere cerebral exhaustion. In other words, the same symptoms may be associated with a state of brain which may pass of quickly, or which may not so pass off. If they pass off quickly - so quickly as to make it certain that they could not have depended upon any organic change in the brain, like apoplexy, or inflammation, or degeneration in one form or another, then they may indicate nothing more than cerebral exhaustion. If they do not pass off then they may indicate a graver state of cerebral exhaustion. That is all that can be said upon the subject, except this - that a state beginning in cerebral exhaustion may end in a graver form of brain-disease. What this state of exhaustion may be $I$ do not pretend to say. I can find no better name for it. And certainly I cannot substitute for it any name implying a dependence on vascular congestion or fulness of any sort-for (as has appeared incidentally more than once in the course of these remarks) there is no good reason for thinking that any one symptom of the disorder points to a state of cerebral congestion, or to an excited over-active condition o the circulation.

There is so much more to be said, that it is difficult to choose what to say and what to leave unsaid. Indeed, all that I can trust myself to do is to say a few words upon one or two practical questions bearing upon the prevention and treatment of cerebral exhaustion, the question of food, the question of walking exercise versus rest, the question of head-work or the contrary, and the question of the proper position of the head when lying down.

I confess to being a heretic in matters of diet. Do what I will I cannot bring myself to accept the current belief that butcher's-meat is food par excellence, and that all other food is little more than "padding". On the contrary, I feel convinced that views and practices in this respect have changed infinitely for the worse during the last few years, and that herein, perhaps, may be found one main reason why various nervous disorders are so numerous and often so difficult to deal with

Few persons with any practical experience, I think, will maintain that the diet of "training", which is relatively rich in lean meat and poor in the other constituents of diet, especially in the oleaginous, can be kept up for any length of time with absolute impunity. The fact, indeed, is simply this, that an extraordinary degree of muscular strength is got up, not by the diet simply, but by the whole plan of training, in six weeks or thereabouts, and that, afterwards, the man in training gets out of "condition" every day, perceptibly losing muscular energy and firmness and pluck, and becoming headachy, feverish, and out of sorts in every way.

Few persons, also, will nowadays be prepared to contend uncompromisingly for Bantingism, which is practically the diet of training carried still farther to extremes on the side of meat ; and not a few, I take it, will have begun to suspect that there may even be something actually hurtful in the practice. For myself, I will simply say that I have quite come to a conclusion on the subject, and that $I$ very much doubt whether there ever was a fallacy which, to use a common phrase, has more effectually "played into the hands" of medical men-of those especially who are sought after by persons suffering from disorders of the nervous system.

These are extreme cases, but, after all, not so extreme as to be beside the purpose. Often, indeed, I meet with persons who are just in the state of those who have been over-training, who are not "up" to any work, bodily or mental, and who tell you that they cannot, for the life of them, tell why they are so, for they have not been taking it out of themselves by work of any kind, and they have been doing all they could to keep up their strength, drinking beef-tea by the quart, eating meat three times a day, and so forth, and who get well with little else to help them when they begin to eat like other people, taking everything, and not too much of anything, and who do not get well until they begin so to do.

The idea which would seem to have had a good deal to do in introducing this habit in question into favour, is one which is now effectually exploded. It was, that the amount of urea in the urine was the measure of tissue-waste - of waste in muscular action especially and that this waste must be met by a proportionate supply of nitrogenised food, of lean meat in particular, for it was natural to suppose that muscle was best fed by muscle. But a very different conclusion to this is necessitated by the laborious and accurate researches of Ed- ward Smith, Parkes, and others in this country, and of Voit and others abroad. In point of fact, it is not true that the amount of urea in the urine is the measure of work done in the system - of muscular work especially. "When", says Dr. Eaward Smith, "the treadmill is worked for a short period-say one hour and a half-in the absence of food, there is no increase in the elimination of urea during that period. When the treadmill is worked with ordinary food, the increase of urea is not more than five per cent. over the quantity which is eliminated by very light work, and with the same food; hence the direct efforts of violent exertion in the production and elimination of urea are not very great under any circumstances. When two different dietaries are provided, varying in nitrogen, but the exertion always remaining the same, there is the greatest excretion of urea with the diet richest in nitrogen. After an unusual dinner-a public dinner, for examplethere is a large excretion of urea. In flesh-feeding animals the nitrogen in the urea represents the nitrogen in the food. When in the absence of food an unusual quantity of water is taken alone, there is an elimin. ation of two or three times the amount of urea that would have occurred if no water had been drunk, and much more than if the ordi. nary food had been taken.* What is influenced by the amount of work, as Dr. Edward Smith points out, is not the amount of urea, but the amount of carbonic acid. It is the amount of carbonic acid, which is in direct proportion to the amount of work done. Thus the quantity of air inspired and of carbonic acid expired are found to be :

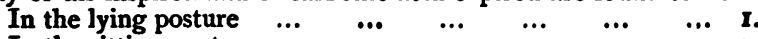

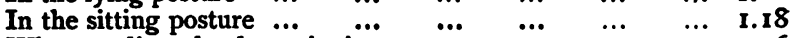

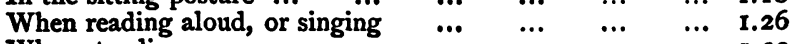

$\begin{array}{llllllll}\text { When standing } \ldots & . . & \ldots & \ldots & \ldots & \ldots & \ldots & 1.26\end{array}$

When walking at two miles an hour ... $\quad \ldots \quad$... $\quad \ldots \quad \ldots \quad$ 3. Io

$\begin{array}{llllll}\text { When walking at three miles an hour } & \ldots & \ldots & \ldots & 3.76\end{array}$

When walking at four miles, and carrying $118 \mathrm{lbs} . \quad \ldots \quad \ldots \quad 5$.

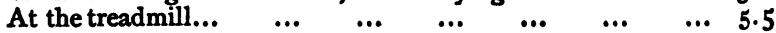

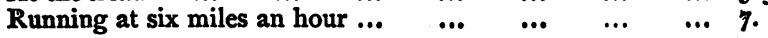

the latter figure showing that the air inspired and the carbonic acid expired may be increased at least sevenfold for a short period. What is influenced by the amount of work, indeed, is not the quantity of urea, but the quantity of carbonic acid, the latter being directly proportionate to the amount of work done ; and this fact, I take it, is full of significance to those who would take upon themselves to say whether a particular diet is right or wrong-significant as showing, perhaps, that the hydrocarbonous elements of food are, to say the least, quite as indispensable as the nitrogenous.

And most assuredly the actual experience of different people is not to be appealed to in proof of a contrary conclusion. The strapping gillie of the Scotch highlands, the chief staple of whose food is oatmeal, with a little milk, is certainly not wanting in muscular strength und power of endurance; on the contrary, as every one will admit who has had to keep up with him in a hard day's deer-stalking, he is " all wind and limb" when his master for the time being is panting and staggering. Nor is the case of the gillie different from that of the Italian labourer, who is seen at work unloading the small coasting corn-vessels on the beautiful shores of the Bay of Naples, whose food is made up chiefly of Indian-corn pudding or polenta, with a little maccaroni and a little oil. This man may be lazy enough, but when called to work he works well enough, as is sufficiently proved by the light way in which he dances from the vessel over the black sand with the heavy sack on his shoulders, and this not once or twice only, but for hour after hour, in the heat of the day even. Nor is it proved that either gillie or lazzarone are less strong than the South American prairie ranger, who eats pounds of meat in the course of the day (he can get little else), and who may even spend the greater part of his days in the saddle ; nay, it may even be a question whether this man is more active than the gillie or lazzaroni. Left to himself, I suspect, he will sleep for days like a gorged deer-hound, or like the gillie who (as happens now and then) has come in for an unusual feast of venison. I remember once a set of these fellows so fed, who slept through several days of bad weather, and who had to be kicked into a state of wakefulness when the weather changed for the better, and they were again wanted. Of course, whiskey in this case complicated the matter a little; but still, as I thought then I still think, that the excess in meat had, to say the least, quite as much to do in promoting sleep as excess in drink. Their case was too evidently a repetition of that of the gorged deerhound, or of any carnivorous animal who has had the chance of eating his fill; men and animals alike sleeping for days, if left alone - until they begin to be hungry again, in fact. And if the case of the South American prairie ranger were gone into fully, it would be found, I suspect, that the pounds of meat consumed by him have had the 
effect the very reverse of invigorating-even that which is seen in the gorged deerhound or gillie.

It is certainly possible for people to enjoy excellent health upon the most different kinds of diet. No doubt there are individuals who take kindly to animal food, and others who do not do so. Most probably a properly mixed diet is best for the generality of persons, in this country at least; but all the evidence, as I can? read it, is against the notion that meat is to be looked upon as the food which must be had at any price. At all events, I cannot help but think that the present practice of urging persons at all weakly, especially children, to eat as much meat as they can, may have not a little to do in causing the development of many nervous disorders, and in deranging the health in many other ways besides-perhaps (as the inquiries of Dr. Parkes would lead one to expect) in causing disease of the liver or kidney or other gland by over-taxing the eliminating powers of these organs.

It is high time, I take it, now that meat of all kinds is only to be had at almost famine prices, that people, and especially the poor, should be taught to think that animal food is not so essential as they believe it to be. It is high time, for instance, that the English poor should be taught to imitate the French poor in their diet. But I must not dilate as I would fain do upon these matters, nor must I attempt to lay down any definite rules of diet. Indeed, all that I must allow myself to do is to reassert my belief that excess of animal food, relative or actual, is a very important cause of many disorders of the nervous system, and that, in the prevention and treatment of these disorders, it is all-important that the oleaginous and farinaceous articles of diet, rather than the nitrogenous, should be fully supplied. I maintain, indeed, as I have long done that the nerve-tissue (which consists in large measure of a kind of fat), is starved if the hydrocarbons be withheld, and that this withholding is one main reason for the speedy breaking-down in training or in Bantingism; and I further believe that this is not the only way in which the want of hydrocarbons operates mischievously. Indeed, the fact that muscular work shows itself in the amount produced, not of urea, but of carbonic acid, convinces me that the hydrocarbons are necessary for action, as well as for nutrition in nerve and muscle-are necessary, perhaps, in keeping up the electrical charge of nerve and muscle, which, as I believe, has muoh to do in nervous action and muscular action. Possibly, also, these hydrocarbons may have some work to do as "floating fuel," though not much ; for if much work of this kind had been required of them, it is not easy to believe that the natives of hot countries would have been so ready to stoke themselves with oily matter-the Hindoo with ghee, for example, and the Italian with olive oil.

I am also very much disposed to maintain that too much stress may be laid upon the importance of walking exercise in very many cases, in cerebral exhaustion among the rest. Of this I am confident, that very many cases of the latter disorder come under notice in which overwalking would seem to be no insignificant cause of breaking down in health, and in which little or no progress is made towards recovery until the patient begins to economise his strength in this direction, in standing quite as much as in walking, perhaps more. It would often seem as if the amount of vital power at the disposal of the individual did not allow much head-work and much leg-work together, though quite sufficient to allow of a fair amount of either kind of work singly; and that, under these circumstances, if the head-work must be done, it is expedient to avoid walking exercise rather than to seek opportunities for taking it, and often to settle down in an easy chair and have a nap rather than to walk at all. It is a common thing for a person suffering from cerebral exhaustion to find that he cannot stand or walk except for a short time, and that, if he persists, he soon becomes faint and breathless and unable to talk, though comparatively fresh and well before he began to walk and stand. It is also a common thing, in such a case, for walking exercise, however moderately indulged in, to be followed by inability to keep the thoughts to this point, or by distressing drowsiness or actual sleep, the walking exercise, in short, having brought on head-symptoms which were not present previously. Upon this point I am thoroughly convinced. I am also constrained to believe -indeed, the simple facts of experience leave me no alternative - that, in very many cases, this persistence in walking and standing, when this opposite rule of rest ought to have been observed, has had mainly to do, not only with bringing on, and keeping up a state of cerebral exhaustion, but with pushing matters to the crisis of hemiplegia. I do not remember a single case of hemiplegia, in any form, in which the attack was not preceded by marked failure in locomotive power, and in which the history did not countenance the notion that the attack might have been averted if there had been more prudence in the matter of walking or standing.
The simple occurrence of hemiplegia must show that the brain had become unequal to the full amount of locomotive work demanded of it; and, if so, then there must surely be grave danger that a jaded brain may break down in hemiplegia if it be overtaxed in this direction of this particular work. In a word, I cannot help but look upon this and other forms of paralysis, in which locomotion is compromised, as in the main preventable when people, in'whom symptoms of cerebral exhaustion are beginning to declare themselves, are more alive to the necessity of saving their strength in this direction of locomotion. At all events, upon one point I have no doubt, namely this; that in many cases of cerebral exhaustion, both with a view to prevention and cure, it is necessary to check rather than to encourage walking exercise.

I am also disposed to think that rest from head-work may be too much insisted upon in cerebral exhaustion and in other cases of the kind. Often and often I have met with patients with jaded brains who have certainly let their minds lie fallow too long. More than one over-worked barrister, who could scarcely drag on until the long vacation, has complained to me that this vacation was too long, and that it would have been better for him if he had returned to his own work sooner, or if he had changed his work. Mere distraction, even travel, is not enough. Weeds will grow apace, under such circumstances; and soon, very soon, the difficulty is to get the mind under cultivation again. What is wanted generally, even at the beginning, is, not that work should be given up altogether, even for a short time, but that it should be moderated in amount or changed. It is given to few to imitate the example of our present premier who, when thoroughly over-wrought at the end of the session, recruited himself by spending a great part of his holiday in writing Fuventus Mundi; but the fact is full of significance in the present place. Indeed, the longer I live the more am I convinced that it is a grave mistake to let the mind lie fallow, even for a short time, not only in the particular case under consideration, but in all cases where head-symptoms have to be dealt with-in epilepsy, for example, no less than in cerebral exhaustion. In epilepsy, indeed, I have long maintained that it is the very gravest blunder in practice to suspend education-that the very basis of successful treatment is only to be laid in education. In the case of an epileptic child, I should be altogether hopeless of arriving at a satisfactory result except by building the plan of treatment on this foundation; and the same feeling would influence me considerably, even in the case of an adult suffering from cerebral disorder, let this disorder be what it may, if in one way or another I could not keep his mind from preying upon itself by providing him with some proper occupation. Of course this notion may be carried too far. Undoubtedly harm, much harm, may be done by pressing the necessity for work too strongly; but, practically, this danger will prove to be small in comparison with that of letting the mind lie fallow.

Much might easily be said upon the importance of attending to the position of the head where the object is to conciliate sleep, or the contrary, and in many other cases. The recumbent position has obviously very much to do with sleep. Undoubtedly sleep may happen in the sitting posture, and even while standing; but these cases are exceptional, and the broad rule remains, that sleep has to do with the recumbent, and wakefulness with the sitting and erect, positions. It is certain, also, that sleep in bed is, as arule, sounder with a low pillow than with a high pillow. If, then, there be a state of wakefulness at night, the head should be kept low; if, on the contrary, undue sleepiness be the state of things then met with, the head should be kept high. Nay, it would even seem to follow that the degree of sleep, and the amount of it, may be regulated by simply taking care that the head is in the right position. The facts would seem to be too obvious to require notice, and yet they certainly have not been realised and applied in practice to the extent which might be expected. It might be expected, for example, that hospital beds would be so constructed as to allow, with a view to the conciliation or counteraction of sleep, of the head being easily depressed or raised; it might be expected that the same want would have been met in one way or other in the construction of ordinary beds; but this expectation as yet is not warranted by the facts. Indeed, certain complicated couches, like those of Alderman or Ward, are the only effectual means of meeting the case in question, and these have really been contrived, not for the purpose of meeting this case, but simply for the purpose of putting the patient in that particular position in which be would be most comfortable. It is, however, not for this latter purpose, but for that of conciliating or counteracting sleep, that I am continually making use of these couches and similar contrivances of a less costly description.* In a case of cerebral exhaustion, or in any

* One of these contrivances may be made by an ordinary carpenter in a very 
other head-affection where prolonged recumbency is a necessary part of the treatment, I scarcely know how to dispense with one of these couches, or one of these contrivances. On an ordinary bed, such a patient is very apt to sleep too much in the day and too little at night - too little at night because he has been sleeping too much in the day ; and, before long, there is no small danger that, for this reason, nightdraughts of various sorts may be introduced into the treatment. On the couch, on the contrary, or on the contrivance which takes its place, all these difficulties are, for the most part, fully met. By raising the head in the day time, the patient remains awake sufficiently to be able to sleep at night ; by depressing the head at bedtime, the conditions are rendered more favourable to sleep during the night; and, as a rule, sleep is to be conciliated in this way-an incalculable advantage-without the help of narcotics. At all events, the facts fully justify these statements. It is possible to fight successfully against either undue drowsiness or undue sleeplessness in this way. In particular, it is possible to fight against undue sleeplessness in this way, and that, too without the equivocal help of narcotics; and, in short, all that I can now do, and must do, is to make plain statements, and leave you to draw your own inferences from them.

\section{CONCERNING SPINAL EXHAUSTION.}

When I began, I did not intend to do more than make a passing allu. sion to spinal exhaustion; and, certainly, at this late moment, I have left myself no alternative. All that I can do, indeed, is to skip the few details into which I had proposed to enter, and to say broadly that the two affections, cerebral exhaustion and spinal exhaustion, are usually associated in a way which makes it difficult to disassociate them altogether ; that they have many symptoms in common ; and that very many of the peculiar symptoms belonging to spinal irritation-on which disorder what I have to say will be found in the article on the subject in Reynolds's System of Medicine - will also be found to belong to spinal exhaustion. The subject is, no doubt, sufficiently intricate, and the diagnosis not always certain ; and this must needs be, for as with cerebral exhaustion, so with spinal exhaustion, it may be taken for granted that any grave organic disorder closely related to it, may be simulated by the state of exhaustion - that the exhaustion, in short, may mark an early stage of this disorder - a statement which is tantamount to saying that these several disorders may not be so grave at first as they may seem to be; that they only become organic at a later stage; that, in short, the early stage, though fully foreshadowing in its symptoms the more serious disease which is about to be established, may be nothing more, and not lead to much more, than what may be spoken of as exhaustion.

No one, Mr. President and Gentlemen, can be more sensible than I am to the short-comings of the present lectures. Much that I wanted to say I have left unsaid ; much that I have said, I well know, might have been more to the point. I can, therefore, only thank you for the patient attention with which you have listened to me, and hope that I may have not spoken altogether in vain, even to those of you who are the least disposed to sympathise with what I have said.

\section{AN IMPROVED MEANS OF PLUGGING THE POSTERIOR NARES.}

By A. GODRICII, M.A., M.R.C.S.

I BEG to submit to professional notice an instrument that I have had constructed by Messrs. Louis Blaise and Co., of 67, St. James's Street, for plugging the anterior and posterior nares in cases of epistaxis. I have long been struck by the unsatisfactory means at our disposal in dealing with such cases. There is, in the first place, owing to its large curve no little difficulty in passing Bellocq's sound, the point of the instrument often hitching on the posterior edge of the floor of the nasal fossa. In the next place, the adjustment of the posterior plug, requiring, as it does, the passing of the surgeon's finger into the fauces,

short time. Three or four ordinary thin deal planks are joined together so as to make a support long cnough and wide enough to bear upon it the bed or mattras upon which the patient has to lie; and then, having first sawn across this support in two places-the one in a line corresponding to the bend at the hips, the other in a line corresponding to the bend at the knees; these three separate pieces are connected by hinges, so as to allow them to be moved upon each other as the three separate pieces forming the invalid bedstead are moved upon each other. This jointed support is placed between the bed or mattrass and the ordinary bedstead: and, being so placed, the head or knees of the patient can be easily raised or depressed, as they are raised or depressed upon the ordinary invalid bed, by placing underneath it, in the right positions, anything which may serve to keep the joints bent 2 the requisite angles. not only causes much distress to the patient, but often entails a more or less severe bite on the operator, as I have found to my cost; and, lastly, when the plug is in position, the string passing from it through the mouth causes so much irritation of the soft palate and fauces, that but few patients have the courage to submit to it.

The instrument consists of a small elastic bag stretched on the end of a hollow style, by means of which it is pushed through the nasal fossa into the pharynx. It is then dilated with ice-cold water by means of the ordinary ear-syringe, the nozzle of which is inserted into a piece of India-rubber tubing tied to the other end of the style. A small piece of thread or twine tied round this prevents the water from escaping. The bag, thus dilated, is now to be drawn well forward into the posterior nares, into which, by its elasticity, it will accurately fit. The anterior India-rubber plug is next to be slid along the style (this is more easily done if the style be previously wetted) into the anterior nares, which it fits like a cork. The cohesion between this plug and the style will, I think, be sufficient to hold both plugs in position; if not, a piece of string tied round the style in front of the anterior plug will ensure perfect security.

When it is necessary to remove the plug, all that the surgeon has to do is to cut the string tied round the piece of India-rubber tubing, when the water will be expelled by the elasticity of the bag, and the instrument may be removed without difficulty.

The instrument, even at its thickest end, where the elastic bag is stretched over the style, is not larger than a No. 6 catheter ; and it can consequently be passed through the nasal fossa without the least diffi. culty, and with very little discomfort to the patient, as I have proved by frequently passing it through my own nose. The style being made of elastic material-in fact, a gum-elastic catheter, and therefore capable of being bent to any curve required-also facilitates the intro. duction of the instrument. When once the instrument is in position, and quiet, it is almost impossible to tell by the sensations alone that there is any foreign body in the nasal fossa at all; the dilatation of the bag causing but little discomfort, being above the sensitive soft palate and fauces.

In designing this instrument, it has been my object to combine sim. plicity and cheapness with perfect efficiency. If I have not fully accomplished my object, I ask any one to suggest any alterations that may bring this instrument nearer to perfection, and enable us to do away with our present barbarous and unsatisfactory plan of plugging the nares.

\section{METEOROLOGY IN ITS BEARING ON HEALTH AND DISEASE.*}

By J. W. MOORE, M.D. Univ. Dub.,

Diplomate in State Medicine, and Ex-Schol. Trin. Coll., Dub. ; Junior Assistant Physician to Cork Street Fever Hospital, Dublin.

IN bygone days Meteorology was limited in its application to appearances in the sky, whether atmospherical or astronomical in their character. Now, however, the word is used to denote a branch of natural philosophy which deals with weather and climate. Its astro. nomical relations are, to a great extent, severed, whilst many terrestrial phenomena are included within its vast domain, and are studied and explained under some of its many branches. Until the last twenty years, the study of meteorology was confined to individuals, amongst whom we notice the names of Aristotle, Theophrastus, and Aratus, in Greece ; Lucretius, Virgil, Pliny, and Cicero, in Italy ; and more lately, within the last two hundred years, those of the discoverer of the barometer, Torricelli ; and of Fahrenheit, Reaumur, and Celsius, the fathers of thermometry. Later still, were Wells, Dalton, and Daniell, whose names are inseparably connected with hygrometry. Finally, the investigation of the isothermal lines was commenced by Humboldt, and almost perfected by Dové.

Within the last twenty years, however, meteorological societies have been founded, first in America, and, more recently, in several countries in Europe, and have collected a vast amount of trustworthy material, which leading meteorologists, as Dové, in Germany; Buys Ballot, in Holland; Maury, in America ; and Lloyd, in our own country, have not been slow to utilise. In 1854 , Dr. Lloyd, the present distinguished

* This paper is an abstract of a lecture-one of a series termed "Afternoon Scientific Lectures"-which was delivered before the Royal Dublin Society, on Saturday, March 8th. 